\title{
Paper stamp checklist tool enhances asthma guidelines knowledge and implementation by primary care physicians
}

\author{
PM Renzi MD¹, H Ghezzo PhD², S Goulet MD¹, E Dorval BPharm¹ ${ }^{1}$ RL Thivierge MD ${ }^{1}$
}

\begin{abstract}
PM Renzi, H Ghezzo, S Goulet, E Dorval, RL Thivierge. Paper stamp checklist tool enhances asthma guidelines knowledge and implementation by primary care physicians. Can Respir J 2006;13(4):193-197.
\end{abstract}

BACKGROUND: The Canadian Clinical Practice Guidelines (CPGs) for the management of asthmatic patients were last published in 1999, with updates in 2001 and June 2004. Large disparities exist in the implementation of these guidelines into clinical practice. OBJECTIVE: The present study evaluated the knowlege of Quebecbased primary care physicians regarding the CPGs, as well as patient outcomes before and after introducing physicians to a new clinical tool - a memory aid in the form of a self-inking paper stamp checklist summarizing CPG criteria and guidelines for assessing asthmatic patient control and therapy. The primary objective of the present study was to assess whether the stamp would improve physicians' knowledge of the CPGs, and as a secondary objective, to assess whether it would decrease patient emergency room visits and hospitalizations.

METHODS: A prospective, randomized, controlled study of 104 primary care physicians located in four Quebec regions was conducted. Each physician initially responded to questions on their knowledge of the CPGs, and was then randomly assigned to one of four groups that received information about the CPGs while implementing an intervention (the stamp tool) aimed at supporting their decision-making process at the point of care. Six months later, the physicians were retested, and patient outcomes for approximately one year were obtained from the Régie de l'assurance maladie du Québec.

RESULTS: The stamp significantly improved physicians' knowledge of the CPGs in all Quebec regions tested, and reduced emergency room visits and hospitalizations in patients who were followed for at least one year.

CONCLUSION: A paper stamp summarizing CPGs for asthma can be used effectively to increase the knowledge of physicians and to positively affect patient outcomes.

Key Words: Asthma; Canadian Clinical Practice Guidelines; CME; Paper stamp tool

\section{Une liste sur un timbre imprimeur pour mieux faire connaître le consensus sur l'asthme aux médecins de première ligne et mieux le leur faire implanter}

HISTORIQUE : Le Consensus canadien sur le traitement de l'asthme a été publié pour la dernière fois en 1999 et mis à jour en 2001 et en juin 2004. Il existe d'énormes disparités dans l'adoption de ce consensus en pratique clinique.

OBJECTIF : La présente étude visait à évaluer les connaissances de médecins québécois de première ligne à l'égard du consensus, ainsi que les issues de patients avant et après la présentation d'un nouvel outil clinique aux médecins, un aide-mémoire sous forme de liste sur un timbre imprimeur auto-encreur résumant les critères et les directives du consensus pour mesurer le contrôle et le traitement du patient asthmatique. L'objectif primaire de la présente étude consistait à mieux faire connaître le consensus sur l'asthme aux médecins, tandis que l'objectif secondaire consistait à estimer s'il réduirait le nombre de consultations à l'urgence et d'hospitalisations des patients.

MÉTHODOLOGIE : Une étude prospective aléatoire et contrôlée auprès de 104 médecins de première ligne de quatre régions du Québec a été menée. Chaque médecin a d'abord répondu à des questions sur ses connaissances au sujet du consensus et a ensuite été assigné de manière aléatoire à l'un des quatre groupes qui recevaient de l'information au sujet du consensus et implantaient une intervention (le timbre imprimeur) visant à soutenir le processus de prise de décision au point de service. Six mois plus tard, les médecins étaient réévalués. L'issue des patients pendant environ un an a également été obtenue auprès de la Régie de l'assurance maladie du Québec.

RÉSULTATS : Le timbre imprimeur a considérablement amélioré les connaissances des médecins à l'égard du consensus dans toutes les régions du Québec évaluées et a réduit les consultations à l'urgence et les hospitalisations des patients suivis pendant au moins un an.

CONCLUSION : Un timbre auto-encreur résumant le consensus sur l'asthme peut être utilisé avec efficacité pour accroitre les connaissances des médecins et améliorer l'issue des patients.
$\mathrm{T}$ ools for translating evidence-based guidelines for the management of asthmatic patients to primary care practice, including computerized systems and action plans, have been ineffective in the United Kingdom and Australia due to low levels of use by physicians (1-3). Guideline dissemination using both written materials and personal visits/discussions by peers has proved effective, and has resulted in asthma guideline use by physicians for approximately $67 \%$ of clinical decisions in the Netherlands; however, the major problem of nonstandardized implementation of the guidelines by the physicians has not been solved (4-6).

The recommendations of the Canadian Clinical Practice Guidelines (CPGs) Consensus Committee regarding treatment of asthmatic patients have been applied nonuniformly throughout Canada by primary care physicians $(7,8)$. Interactive continuing medical education (CME) appears to be effective for training physicians on some, but not all, aspects of the CPGs $(9,10)$. CME courses have been found to have a weak 
TABLE 1

Canadian Clinical Practice Guidelines information dissemination to randomly assigned groups of Quebec primary care physicians

\begin{tabular}{ll}
\hline Group & $\begin{array}{l}\text { Method of disseminating Canadian Clinical } \\
\text { Practice Guidelines information }\end{array}$ \\
\hline 1 & CME event that focused on the stamp \\
Written stamp instructions given at the CME event & Verbal encouragement given to use the stamp at will \\
& Asked to have six of their patients with asthma to sign informed \\
& consent forms that allowed their charts to be reviewed at the \\
& end of the study, and asked to use the stamp regularly on \\
& every follow-up visit \\
& CME event that focused on the stamp \\
& Written stamp instructions given at the CME event \\
& Verbal encouragement given to use the stamp at will \\
3 & Stamp sent by mail \\
& Written stamp instructions sent by mail \\
& Written Canadian Clinical Practice Guidelines sent by mail as \\
& per groups 1 to 3
\end{tabular}

CME Continuing medical education

or short-term impact on the application of the asthma CPGs to current medical practice, mainly because primary care physicians do not have the time or resources to implement the CPGs easily (7,11-13). A recommendation from these studies is to use CME training jointly with interventions that follow-up with patients or that provide memory aids for physicians.

Recently, Clark et al (14) showed a positive, long-term effect of medical training seminars based on the recommendations of the CPGs, coupled with patient-doctor communication training. The intervention described by Clark et al (14) involved a better utilization of the medical visit time through the use of a physician's checklist and associated plan of action, which also had an impact on the education of the asthmatic patient. The limited time $(15 \mathrm{~min})$ allotted for a patient visit was seen as a limiting factor in the implementation of the CPGs, and it was suggested that tools should be developed to facilitate and improve the care of patients during a visit (15).

We have developed a self-inking paper stamp memory aid tool for use by primary care physicians when they examine their asthmatic patients. The stamp provides a checklist for the physician that summarizes the eight CPG criteria for asthma control and includes questions regarding the patient's environment at home and work, and about cigarette smoking. The stamp also helps the physician to remember anti-inflammatory and add-on therapies, and to refer the patient to an asthma education centre for training, as well as to create a written action plan. We believe that this stamp is small enough to find a place on the physician's desk and its daily use will increase the uniformity of asthma treatment across Canada.

The primary objective of the present study was to verify whether the stamp increased the knowledge of the CPGs among primary care physicians, and whether improved knowledge was translated into improved patient outcomes by assessing emergency room (ER) visits and hospitalizations. We tested whether the stamp was more effective in translating the CPGs to the clinic than the traditional method of sending a copy of the CPGs by mail to primary care physicians. We also assessed the effects of adding an associated CME event and a physician incentive (ie, a review of the charts of six patients at the end of the study).

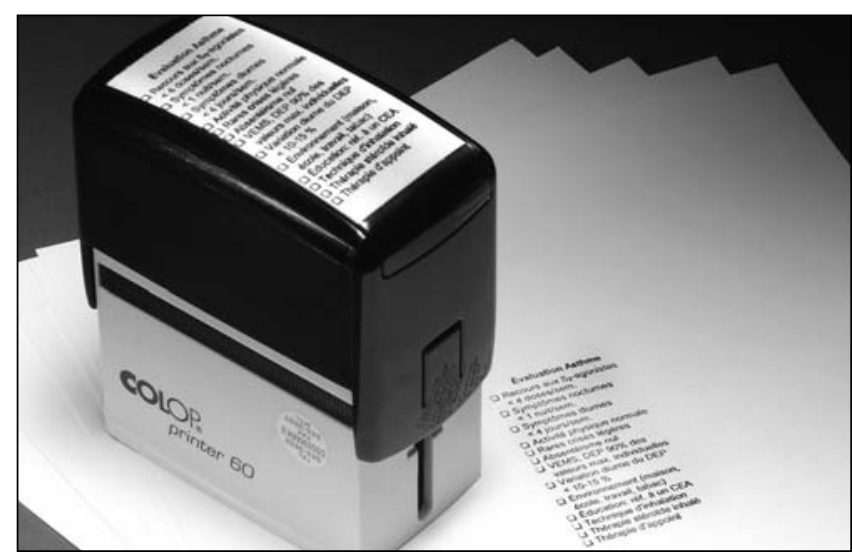

Figure 1) Self-inking paper stamp checklist tool summarizing the Canadian Clinical Practice Guidelines for physician assessment of asthmatic patient control and therapy. The content of the stamp is given in Tables 3 and 4

\section{METHODS}

One hundred four primary care physicians in private practice in four different regions of Quebec, who normally saw at least one asthmatic patient per week, were recruited into the study between August and September 2002. The physicians were chosen in regions that were coded as red in Quebec, as per a cartography study by Lajoie et al (16), where an excess of asthmatic patients were consulting ERs and hospitalized. After signing informed consent forms, the physicians were asked to answer, in writing, two questions regarding their current asthmatic patient management methods and their knowledge of the CPGs: please describe the eight criteria of asthma control; and what pharmacological and nonpharmacological interventions can be applied to improve patients with asthma? The physicians were then randomly assigned to the four groups listed in Table 1 and, subsequently, they received the CPG information in the different forms indicated in the Table. Groups 1 to 4 all received the traditional written copy of the CPGs by mail. Group 3 also received the stamp by mail, along with a one-page written instruction sheet. Groups 1 and 2 were introduced to the paper stamp and given a written stamp instruction sheet during a CME event. The CME event consisted of a 30 min lesson on the CPGs, followed by a demonstration of the use of the paper stamp for controlling asthmatic patients in a clinical setting. During the CME event, groups 1 and 2 received verbal encouragement to use the stamp at will. To improve compliance with the stamp in group 1 , the physicians were also asked to use the stamp consistently when examining six patients of their choice; informed consent was obtained from these patients, which allowed their charts to be reviewed at the end of the study. On average, the group 1 physicians obtained informed consent from 2.4 patients; however, their charts were not reviewed.

The self-inking paper stamp that was given to physicians (Figure 1) was designed to be stamped onto the patient's chart at each visit. The stamp was approximately $8.5 \mathrm{~cm}$ long and $5.5 \mathrm{~cm}$ wide, and consisted of a description of the eight criteria for asthma control, followed by a reminder to check the environment at home and work, as well as smoking status, inhaler technique, referral to an asthma education centre, anti-inflammatory and add-on therapies, and a written action plan.

Thirty-six physicians were enrolled in Montérégie, 17 in Laval, 12 in Montreal, and 39 in Saguenay and Lac St-Jean, Quebec. Physicians working in clinics with six or fewer other physicians were chosen for the study to avoid biasing the study results in favour of the opinions of a single, large group of physicians working 
TABLE 2

Comparison of the initial questionnaire baseline results (mean scores) between regions in Quebec

\begin{tabular}{lccc}
\hline & $\begin{array}{c}\text { Question 1 } \\
\text { (asthma control) }^{*}\end{array}$ & $\begin{array}{c}\text { Question 2 } \\
\text { (Educ/Rx) }^{*}\end{array}$ & $\begin{array}{c}\text { Total } \\
\text { (maximum of 16) }^{\text {(momal }}\end{array}$ \\
\hline Laval & 2.6 & 2.4 & 5.0 \\
Lac St-Jean & 1.2 & 2.5 & 3.7 \\
Montreal & 3.6 & 2.2 & 5.8 \\
Montérégie & 2.5 & 2.4 & 4.9 \\
Saguenay & 1.6 & 3.4 & 5.0 \\
Total mean \pm SD & $2.2 \pm 1.7$ & $2.6 \pm 1.5$ & $4.8 \pm 2.1$ \\
\hline
\end{tabular}

*Maximum score of 8. Educ/Rx Educational and therapeutic criteria

at one major clinic. The median year of graduation of the physicians was 1981, and there were no differences with regard to age and year of graduation between groups or between regions. The second meeting with the physicians occurred approximately six months after the first meeting and was conducted by the study coordinators, who asked the physicians to complete a second questionnaire. The second questionnaire asked the same two questions as the initial questionnaire, as well as questions on their use and knowledge of the content of the paper stamp. Physicians from groups 1 to 3 were encouraged to use the stamp for another six months, and the physicians from all four groups were invited to a CME event one year after enrollment, where the results of the study questionnaires at enrollment and six months later were presented.

After approval from the Ethics Committee (CHUM Hospitals, University of Montreal, Montreal, Quebec) and the Conseil d'accès à l'information, coded information on the visits of asthmatic patients was obtained from physicians in each group. In addition, patient information was obtained on the number of ER visits and hospitalizations for asthma during 2001, as well as after the patients were seen by a physician from one of these groups. Random assignment to all four groups was performed by region with a pre-established code. The results of both questionnaires, as well as the patient outcomes obtained from the Régie de l'assurance maladie du Québec, were analyzed using R (17). Results were considered significant at $\mathrm{P}<0.05$.

\section{RESULTS}

Table 2 shows the analysis of physician responses to the initial two questions. No difference was found among the primary care physicians from different regions of Quebec in terms of their knowledge of criteria for asthma control, and knowledge of educational and therapeutic interventions. The physicians reported knowing an average of 2.2 of the eight asthma control criteria, and an average of 2.6 of the eight predetermined educational and therapeutic interventions that are recommended in the CPGs for asthma. Thus, the total average scores for the asthma control and educational and therapeutic questions were 4.8 out of the 16 expected answers. No difference in responses was found between the randomly assigned groups, and no correlation was found between results and the year of graduation.

Tables 3 and 4 present a list of asthma control criteria and educational and therapeutic interventions in the same order as presented on the paper stamp. On the right, by region, are the minimum and maximum percentages of physicians reporting each criterion. As can be seen in the third column of Table 3, the number of physicians who reported each specific asthma control criterion varied depending on the criterion selected and
TABLE 3

Baseline knowledge of the asthma control criteria of the Canadian Clinical Practice Guidelines among primary care physicians

\begin{tabular}{|c|c|c|}
\hline Criteria & Characteristics & $\begin{array}{c}\text { Reported by } \\
\text { physicians }(\%)^{*}\end{array}$ \\
\hline Short-acting beta-2-agonists & $<4$ doses/week & 38 to 91 \\
\hline Night-time symptoms & $<1 \mathrm{night} /$ week & 13 to 45 \\
\hline Daytime symptoms & $<4$ days/week & 0 to 27 \\
\hline Physical activity & Normal & 27 to 64 \\
\hline Exacerbations & Mild, infrequent & 5 to 27 \\
\hline Absenteeism & Nil & 7 to 63 \\
\hline $\mathrm{FEV}_{1}$ or PEF & $90 \%$ of personal best or greater & 0 to 38 \\
\hline Diurnal variability in PEF & Less than $10 \%$ to $15 \%$ & 3 to 18 \\
\hline
\end{tabular}

${ }^{*}$ Results are shown as a range based on the region with the lowest and highest percentage. FEV 1 Forced expiratory volume in $1 \mathrm{~s}$; PEF Peak expiratory flow

TABLE 4

Baseline knowledge of the educational and therapeutic criteria of the Canadian Clinical Practice Guidelines among primary care physicians

\begin{tabular}{lc}
\hline Criteria & Reported by physicians (\%) \\
\hline Home environment & 38 to 81 \\
Work environment & 0 to 11 \\
Smoking & 26 to 48 \\
Referral to an asthma education centre & 9 to 57 \\
Inhaler technique & 31 to 60 \\
Inhaled corticosteroid/anti-inflammatory & 27 to 53 \\
Additional therapy & 9 to 28 \\
Action plan & 13 to 46
\end{tabular}

${ }^{*}$ Results are shown as a range based on the region with the lowest and highest percentage

the region where the physician was practicing. For example, in the four regions that were studied, between $38 \%$ and $91 \%$ of physicians reported the control criterion of short-acting beta-2agonist use fewer than four times per week. Interestingly, few physicians in each region (between 13\% and 45\%) reported night-time awakenings less than once per week.

Table 4 shows the CPG educational and therapeutic criteria that are also listed on the paper stamp (column on the left), and the lowest and highest percentage of physicians (among the four regions studied) who reported these criteria at the beginning of the study (column on the right). Again, the percentage of physicians reporting this information varied widely depending on the criterion and the region being examined. Tables 3 and 4 show that at the beginning of the study, the physicians did not have a full knowledge of the CPGs, despite extensive educational campaigns that have been ongoing in Quebec for at least 10 years.

Table 5 presents, by group, the results of the analysis of the second questionnaire (same two questions) that was completed six months after the beginning of the study. There was no significant improvement in the knowledge of the control group (group 4), which received only the consensus guidelines by mail. In controls, knowledge of the control criteria increased from an average of 2.2 to 3.0 of the eight criteria, whereas knowledge of educational and therapeutic interventions decreased from an average of 2.6 to 2.1 criteria, with the total responses improving by only $6 \%$. Significant improvement was 


TABLE 5
$\begin{aligned} & \text { Knowledge of Canadian Clinical Practice Guidelines in the } \\
& \text { four randomly assigned primary care physician groups, } \\
& \text { six months after the beginning of the study }\end{aligned}$
\begin{tabular}{lccc}
\hline Group & Asthma control criteria* & Educ/Rx ${ }^{\dagger}$ & Total (maximum of 16) \\
\hline 1 & 5.2 & 3.9 & 9.1 \\
2 & 4.5 & 3.7 & 8.2 \\
3 & 4.5 & 3.3 & 7.8 \\
4 & 3.0 & 2.1 & 5.1 \\
\hline
\end{tabular}

${ }^{*}$ An average baseline score of 2.2 (maximum score of 8); ${ }^{\dagger}$ An average baseline score of 2.6 (maximum score of 8). Educ/Rx Educational and therapeutic criteria

shown in the physicians' knowledge of the CPGs in all the groups of physicians that received a stamp.

The knowledge of CPGs improved in direct relationship to the amount of intervention that was associated with the stamp (Table 5). Group 3 (stamp sent by mail with instructions) had a total score of 7.7 out of 16 , which, compared to baseline ( 4.8 out of 16 ), represented an improvement of $60 \%$. Group 2 (stamp with CME event) had a total score of 8.2 out of 16 , which represented an improvement of $71 \%$. Finally, group 1 (stamp with CME event and incentive) had a total score of 9.0 out of 16 , which represented an improvement of $87 \%$. It is interesting that the majority of improvement could be accounted for in group 3, in which physicians were only sent the stamp by mail.

The impressions of the physicians on the utility of the stamp were obtained. Seventy-four per cent of the physicians kept the stamp on their desk, 13\% in a drawer and the others in different places. Eighty-four per cent of the physicians thought the stamp was useful in daily practice and, on average, physicians reported using the stamp for $54 \%$ of their patients with asthma. Finally, $87 \%$ of physicians reported that they would continue to use the stamp at the end of the study.

Many studies have reported improvement in physicians' knowledge with different therapeutic interventions, but few have reported changes in outcomes. Thus, it was assessed whether an improvement in physician knowledge was translated into an improvement in patient outcomes by determining the change in the number of ER visits and hospitalizations for the patients with asthma that were followed by the physicians of the different groups over a 12-month period. Table 6 shows the effect of the intervention (the paper stamp checklist that is shown in Figure 1) on the number of ER visits and hospitalizations, normalized per year, for all of the asthmatic patients who had been seen by their physician in 2001, and who were seen by their physician at their clinic after being enrolled into the study. The patients with asthma that were seen by the physicians in groups 1 to 3 (taken together), who received the stamp, had significantly less ER visits (7.8\% per year, $\mathrm{P}=0.009)$ and tended to have less hospitalizations ( $2.2 \%$ per year, $\mathrm{P}=0.09$ ) than the asthmatic patients seen by group 4 physicians, who did not receive the stamp $(13.5 \%$ ER visits per year and $4 \%$ hospitalizations per year). The effects of the CME event and the incentive (ie, the reviewing of patient charts at the end of the study) on outcomes were modest at best, which agrees with previous studies that showed that CME training may not be very effective or beneficial in the long term $(18,19)$. It should be noted that the positive effects of the stamp were seen even in patients of group 3 physicians, such that the number of hospitalizations $(2.4 \%)$ tended to be lower than in the control group 4 patients $(4.0 \%)$; however, the number of ER visits were similar.
TABLE 6

Effect of the stamp on emergency room (ER) visits and hospitalizations for asthma

\begin{tabular}{|c|c|c|c|c|}
\hline & Group 1 & Group 2 & Group 3 & Group 4 \\
\hline Intervention (stamp) & Yes & Yes & Yes & No \\
\hline $\begin{array}{l}\text { Intervention } \\
\text { (stamp + CME event) }\end{array}$ & Yes & Yes & No & No \\
\hline Mailing & - & \multicolumn{3}{|c|}{ instructions by mail mail ${ }^{\dagger}$} \\
\hline Enrolled 6 patients & Yes & No & No & No \\
\hline $\begin{array}{l}\text { Patients seen } \\
\text { at clinic, } \mathrm{n}\end{array}$ & 252 & 567 & 571 & 222 \\
\hline ER visits, n (\%) & $20(7.9)$ & $35(6.2)$ & $54(9.4)$ & $30(13.5)$ \\
\hline Hospitalizations, n (\%) & $9(3.6)$ & $8(1.4)$ & $14(2.4)$ & $9(4.0)$ \\
\hline Summary & \multicolumn{3}{|c|}{ Groups 1 to 3} & Group 4 \\
\hline Patients seen at clinic, $n$ & \multicolumn{3}{|c|}{1390} & 222 \\
\hline ER visits, $\mathrm{n}(\%)$ & \multicolumn{3}{|c|}{$109(7.8)^{\star \star}$} & $30(13.5)$ \\
\hline Hospitalizations, n (\%) & \multicolumn{3}{|c|}{$31(2.2)^{\star}$} & $9(4.0)$ \\
\hline
\end{tabular}

${ }^{*} P=0.09$ for groups 1 to 3 versus group $4 ;{ }^{* *} P=0.009$ for groups 1 to 3 versus group 4; the Canadian Clinical Practice Guidelines (CPGs) were also sent by mail to groups 1 to 3. CME Continuing medical education

No differences were found in the percentages of ER visits and hospitalizations between patients followed by groups 1 to 3 physicians and those followed by group 4 physicians when the analysis included patients who had not been seen by the same physicians for asthma in the previous year (2001). Thus, the stamp seems to be ineffective when assessing outcomes in a group of patients that probably included new patients, patients who do not come to regular follow-up visits for their disease and walk-in patients. The number of return visits to the physician's office after the first visit for asthma was also assessed. Thirty-nine per cent of patients with asthma returned for a follow-up visit to physicians from groups 1 to 3 over the study period, whereas in group $4,27 \%$ of patients returned to see their physician $(\mathrm{P}=0.029)$.

\section{DISCUSSION}

The traditional method of disseminating the information contained in the CPGs has been to send primary care physicians a written copy of the CPGs, along with written instructions. This approach has resulted in large differences in the uniformity of implementation of the CPG recommendations in medical practices across the country $(7,20)$. To improve the situation, we created a new clinical tool - a memory aid in the form of a paper stamp checklist for primary care physicians to use at the point of care. The stamp checklist summarizes the updated CPG criteria and guidelines for treating asthmatic patients (8), and thus, provides physicians with a standardized list of key questions to ask while examining their patients during the limited time allotted for patient visits ( $15 \mathrm{~min}$ ). The use of the stamp allows physicians to rapidly make the decisions required to determine whether asthmatic patients are controlled or uncontrolled. If controlled, the physician could continue the medication regimen; however, if uncontrolled, the physician could change the medications or refer the patient to a specialist.

The physicians' acceptance of using the stamp to help them to implement the guidelines in a standardized manner and to manage their asthmatic patients in daily clinical practice was high $(84 \%)$. In this regard, it should be noted that the stamp 
appears to be superior to other systems, such as computerized systems, action plans, and combinations of written documents and personal approaches by peers. The latter have had either very low usage rates by primary care physician or problems with nonuniform implementation of the recommendations by the physicians $(1-3,21,22)$.

The present study showed that use of the paper stamp checklist tool by primary care physicians in Quebec significantly improved their knowledge of the CPGs for asthmatic patient treatment. The use of the stamp by physicians also increased the standardization of asthmatic patient treatment within the group of physicians tested, significantly reduced the number of ER visits and tended to reduce hospitalizations for the patients who had been followed for at least a year. The effect of the CME event that combined CPG education with a demonstration of the use of the stamp in a clinical setting was modest. There was no effect on outcomes when all asthmatic patients were included in the analysis. We may speculate that the patients who were not seen for asthma in the previous year were either new patients, noncompliant patients (not coming regularly to follow-up visits) or walk-in patients. These three groups of patients are expected to be less compliant, and the physicians may have had more time to educate those patients who come to regular visits.

\section{REFERENCES}

1. Douglass J, Aroni R, Goeman D, et al. A qualitative study of action plans for asthma. BMJ 2002;324:1003-5.

2. Eccles M, McColl E, Steen N, et al. Effect of computerised evidence based guidelines on management of asthma and angina in adults in primary care: Cluster randomised controlled trial. BMJ 2002;325:941-4.

3. Currie GP, Devereux GS, Lee DK, Ayres JG. Recent developments in asthma management. BMJ 2005;330:585-9.

4. Davis DA, Thomson MA, Oxman AD, Haynes RB. Changing physician performance. A systematic review of the effect of continuing medical education strategies. JAMA 1995;274:700-5.

5. Davis DA, Taylor-Vaisey A. Translating guidelines into practice. A systematic review of theoretic concepts, practical experience and research evidence in the adoption of clinical practice guidelines. CMAJ 1997;157:408-16.

6. Bero LA, Grilli R, Grimshaw JM, Harvey E, Oxman AD, Thomson MA; The Cochrane Effective Practice and Organization of Care Review Group. Closing the gap between research and practice: An overview of systematic reviews of interventions to promote the implementation of research findings. BMJ 1998;317:465-8.

7. Jin R, Choi BC, Chan BT, et al. Physician asthma management practices in Canada. Can Respir J 2000;7:456-65.

8. Lemiere C, Bai T, Balter M, et al. Adult Asthma Consensus Guidelines Update 2003. Can Respir J 2004;11(Suppl A):9A-18A.

9. Zeitz HJ. Problem based learning: Development of a new strategy for effective continuing medical education. Allergy Asthma Proc 1999;20:317-21.

10. Veninga CC, Lagerlov P, Wahlstrom R, et al; Drug Education Project Group. Evaluating an educational intervention to improve the treatment of asthma in four European countries. Am J Respir Crit Care Med 1999;160:1254-62.

11. Conway A. Adherence and compliance in the management of asthma: 1. Br J Nurs 1998;7:1313-5.
Interestingly, the benefits of the stamp were seen even in the physician group that was sent the stamp by mail (along with a written instruction sheet) but that did not attend the CME event. The results of the present study suggest a high benefit at a low cost for the use of the stamp in the clinics of primary care physicians. Based on the results published by Lajoie et al (16), the stamp could potentially reduce health care costs across Canada by decreasing the yearly number of ER visits for asthma by 5.7 visits per 100 patients and by decreasing the yearly number of hospitalizations for asthma by 1.8 hospitalizations per 100 patients, at least in regions where visits to the ER and hospitalizations are frequent, such as the red zones of Quebec (high morbidity mapping; see Lajoie et al [16]) where this study was performed.

ACKNOWLEDGMENTS: The authors thank the research coordinators Muriel Grenon, Francine Robinson and Fortunée Taieb, as well as Marie Josée Samson, for all their contributions to the success of this study.

FUNDING: Funded by the Towards Excellence in Asthma Management (TEAM) project of the Quebec Asthma Education Network.

12. Crim C. Clinical practice guidelines vs actual clinical practice: The asthma paradigm. Chest 2000;118(Suppl 2):62S-4S

13. Ockene JK, Zapka JG. Provider education to promote implementation of clinical practice guidelines. Chest 2000;118(Suppl 2):33S-9S.

14. Clark NM, Gong M, Schork MA, et al. Long-term effects of asthma education for physicians on patient satisfaction and use of health services. Eur Respir J 2000;16:15-21.

15. Feder G, Griffiths C, Highton C, Eldridge S, Spence M, Southgate L. Do clinical guidelines introduced with practice based education improve care of asthmatic and diabetic patients? A randomised controlled trial in general practices in east London. BMJ 1995;311:1473-8.

16. Lajoie P, Laberge A, Lebel G, et al. Cartography of emergency department visits for asthma - Targeting high-morbidity populations. Can Respir J 2004;11:427-33.

17. R Development Core Team. R: A Language and Environment for Statistical Computing. Vienna: R Foundation for Statistical Computing, 2005.

18. Davis DA, Thomson MA, Oxman AD, Haynes RB. Evidence for the effectiveness of CME. A review of 50 randomized controlled trials. JAMA 1992;268:1111-7.

19. Kennedy T, Regehr G, Rosenfield J, Roberts SW, Lingard L. Exploring the gap between knowledge and behavior: A qualitative study of clinician action following an educational intervention. Acad Med 2004;79:386-93.

20. Cabana MD, Rand CS, Powe NR, et al. Why don't physicians follow clinical practice guidelines? A framework for improvement. JAMA 1999;282:1458-65.

21. DiCenso A, Virani T, Bajnok I, et al. A toolkit to facilitate the implementation of clinical practice guidelines in healthcare settings. Hosp Q 2002;5:55-60.

22. Grol R. Successes and failures in the implementation of evidence-based guidelines for clinical practice. Med Care 2001;39(Suppl 2):II46-54. 


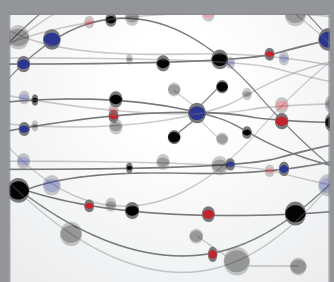

The Scientific World Journal
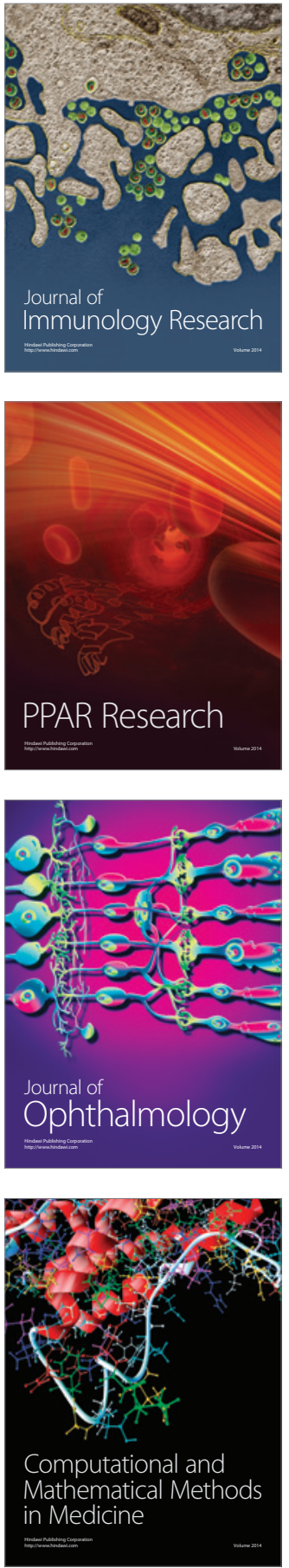

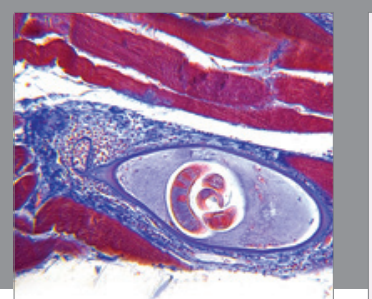

Gastroenterology Research and Practice

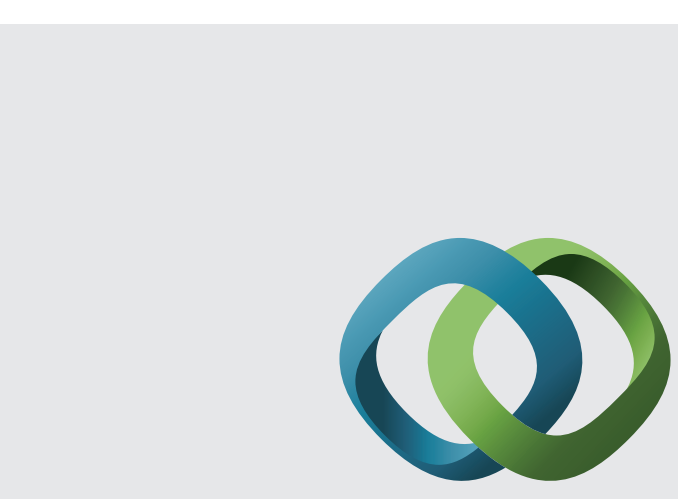

\section{Hindawi}

Submit your manuscripts at

http://www.hindawi.com
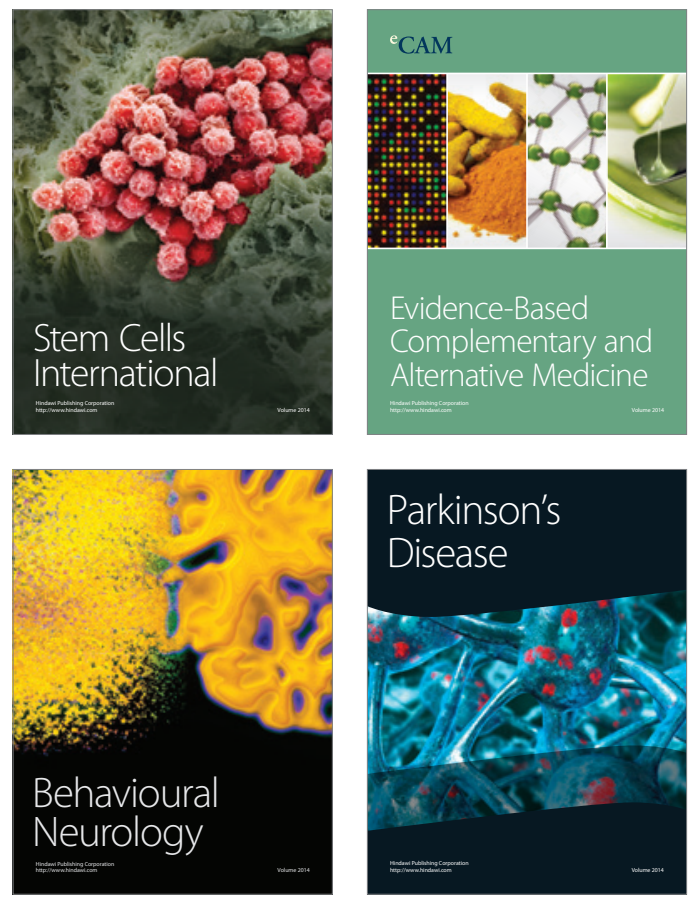
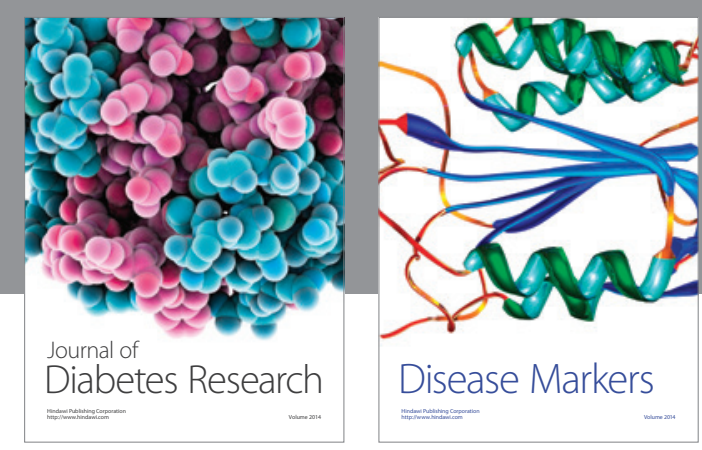

Disease Markers
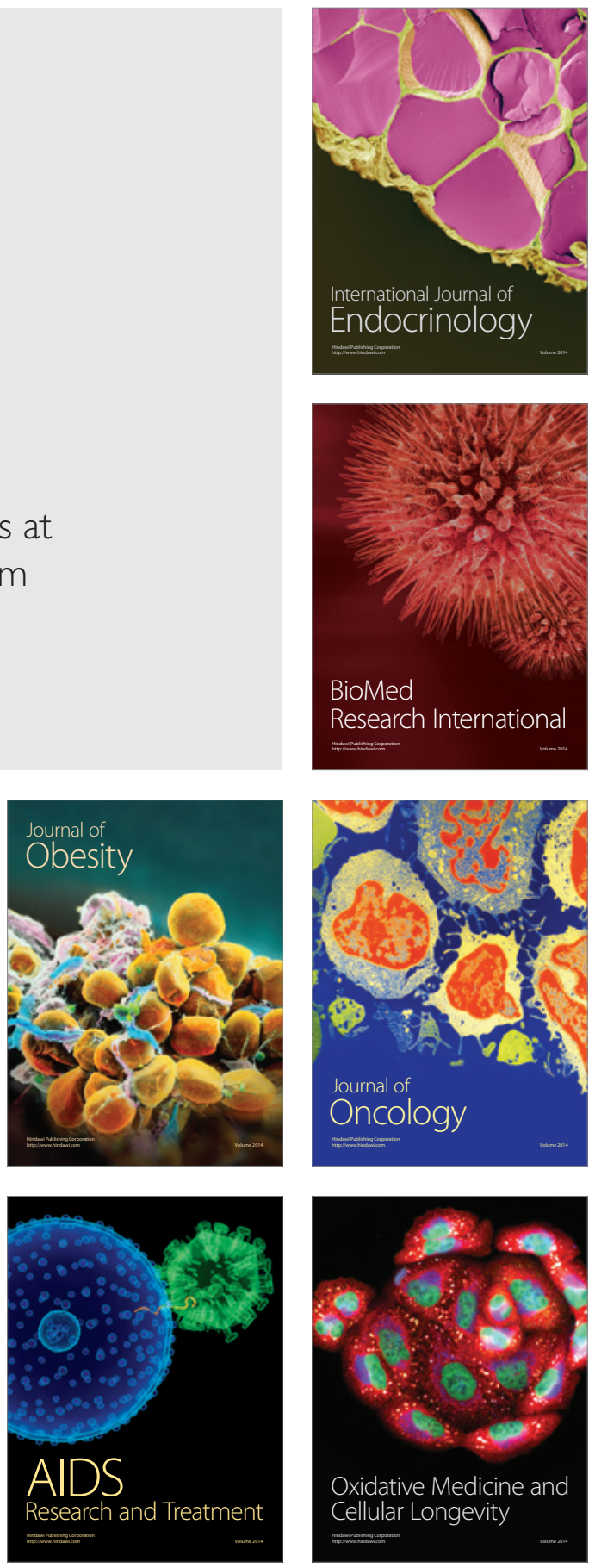